\title{
Correlation between male and female genital tuberculosis: a prospective analytical study
}

\author{
Aarushi Chaudhary ${ }^{1 *}$, Prabhjot Kaur ${ }^{3}$, Richa Kansal ${ }^{1}$, Vikas Dhillon ${ }^{2}$, Isha Bansal ${ }^{1}$
}

\author{
${ }^{1}$ Department of Obstetrics and Gynecology, ${ }^{2}$ Department of ENT, Kalpana Chawla Government Medical College, \\ Karnal, Haryana, India \\ ${ }^{3}$ Consultant, Guru Nanak Hospital and Divine India IVF Centre and Research Institute for Human Reproduction, \\ Karnal, Haryanan, India
}

Received: 05 January 2021

Revised: 14 February 2021

Accepted: 15 February 2021

\author{
*Correspondence: \\ Dr. Aarushi Chaudhary, \\ E-mail: prof.aarushi@gmail.com
}

Copyright: (C) the author(s), publisher and licensee Medip Academy. This is an open-access article distributed under the terms of the Creative Commons Attribution Non-Commercial License, which permits unrestricted non-commercial use, distribution, and reproduction in any medium, provided the original work is properly cited.

\begin{abstract}
Background: Genital tuberculosis is an unusual extrapulmonary manifestation of tuberculosis, often seen in middleaged men with renal or pulmonary disease. The most common male genital sites of tuberculous infection are the epididymis and prostate. It is also an important cause of female infertility in the world, especially in developing countries. Majority of infertility cases are due to involvement of the fallopian tubes. Hardly any study has been done to establish correlation between male and female genital TB. We have evaluated the same in severe oligospermic/ azoospermic males and established a definite correlation. Objective was to establish a definite correlation between female and male genital tuberculosis in patients with male factor infertility.

Methods: 100 severe oligozoospermic/azoospermic males presenting with infertility between April 2011 and January 2016 were enrolled and worked up for genital tuberculosis. Their female partners were worked up for female genital TB and correlation established.

Results: Out of 100 patients with severe oligospermia or azoospermia who tested positive for TB quantiferon gold test. $18 \%$ female partners tested positive for TB quantiferon gold test.

Conclusions: Tubercular work up of both partners is desired in couples with male factor infertility especially in long standing infertility to achieve optimum pregnancy outcome with ART.
\end{abstract}

Keywords: ART, Infertility, Tuberculosis

\section{INTRODUCTION}

Tuberculosis (TB) remains a major public health problem globally with 10 million persons developing active TB each year with 1.33 million deaths. ${ }^{1}$ Most (85\%) TB deaths occur in developing countries, especially Asia $(55 \%)$ and Africa $(30 \%)$ with most $(75 \%)$ cases being from 15-45 years age group. ${ }^{1}$ The Revised National TB Control Programme (RNTCP) of India has incorporated the DOTS strategy all over India by the end of 2005 diagnosing about 71 per cent cases and curing above 87 per cent cases with a seven-fold reduction in mortality. ${ }^{2}$ Genitourinary TB is responsible for 27.1 per cent cases of
EPTB with genital TB being seen in nine per cent cases. ${ }^{3}$ The exact incidence of FGTB is not known due to underreporting of cases, asymptomatic cases, vague symptomatology and the lack of reliable diagnostics with high sensitivity. ${ }^{4-7}$ Genital tuberculosis is an unusual extrapulmonary manifestation of tuberculosis, often seen in middle-aged men with renal or pulmonary disease. The most common male genital sites of tuberculous infection are the epididymis and prostate; the testicle is infected in a lower proportion of cases. ${ }^{8}$ Clinical findings are variable, but commonly include dysuria with sterile pyuria, oligo-zoospermia, necrozoospermia, azoospermia, usually unilateral painless/painful scrotal swelling, 
thickened scrotal skin. $90 \%$ cases presenting as chronic epididymo-orchitis can be attributed to TB. And the most common manifestation of genitourinary $\mathrm{TB}$ in males is epididymitis with/without orchitis. Initial diagnosis is often incidentally made on pathological specimens and confirmed with nucleic acid amplification and cultures. ${ }^{9}$ Genital tuberculosis (TB) is an important cause of female infertility in the world, especially in developing countries. Majority of infertility cases are due to involvement of the fallopian tubes (92\%-100\%), endometrial cavity (50\%), and ovaries (10\%-30\%); cervical and vulvovaginal TB are uncommon. Female genital TB has characteristic radiological appearances based on the stage of the disease process (acute inflammatory or chronic fibrotic) and the organ of involvement. ${ }^{10}$ Hardly any study has been done to establish correlation between male and female genital TB. We have evaluated the same in severe oligospermic/ azoospermic males and established a definite correlation.

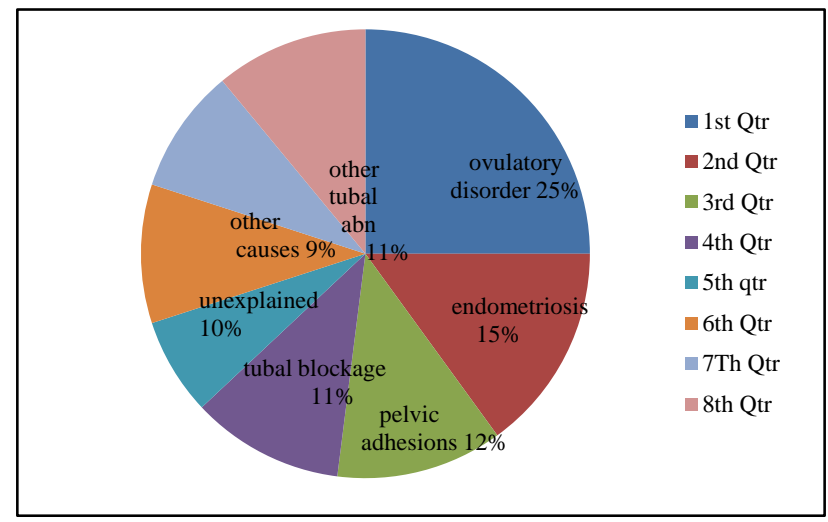

Figure 1: Causes of female infertility.

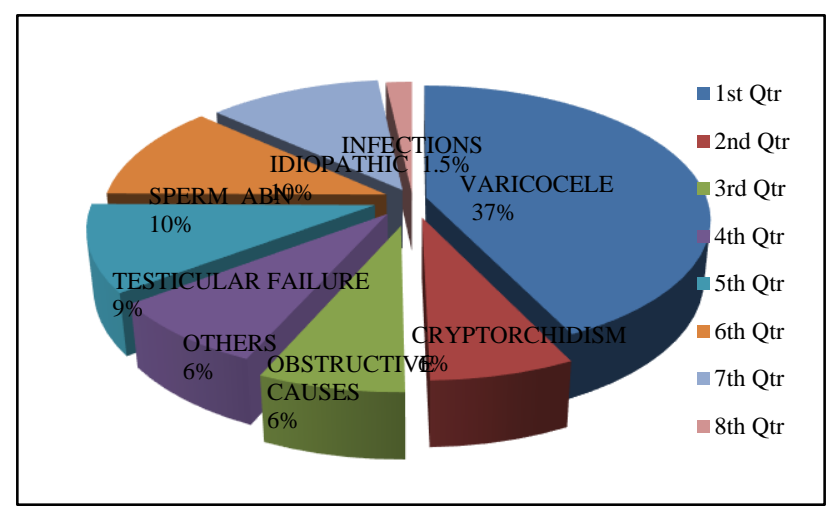

Figure 2: Causes of male infertility.

\section{Objective}

To establish correlation between male and female genital tuberculosis in patients with male factor infertility.

\section{METHODS}

It was a prospective analytical study done at Divine India IVF Centre and Research Institute for Human
Reproduction, Karnal from April 2011 to January 2016. Informed consent was taken from both male and female partners. Ethical clearance was obtained from institute's ethics committee. 100 severe oligozoospermic/ azoospermic (WHO criteria) males in the age group 25 to 45 years (diagnosed on semen analysis after three days of abstinence) presenting with primary or secondary infertility were enrolled and worked up for genital tuberculosis. Diagnosis established by TB quantiferon gold test. All samples were sent to same lab for analysis. Their female partners were worked up for infertility, investigations including complete blood count, liver and kidney function tests, random blood sugar, thyroid function tests, serum prolactin, pelvic ultrasound, chest $\mathrm{x}-$ ray, endometrial biopsy, hysterosalpingography and hysteroscopy was done for all. Patients with intrauterine synechiae, cornual block and periosteal fibrosis, suspicious of TB on hysteroscopy were tested with TB quantiferon gold test and female genital TB established.

\section{RESULTS}

Out of 100 patients with severe oligospermia or azoospermia as per WHO criteria, $35 \%$ tested positive for TB quantiferon gold test. $18 \%$ female partners tested positive for TB quantiferon gold test. Out of these, 35\% had intratubal pathology like ostial stenosis, fibrosis, thickening of tubes, hydrosalpinx, pyosalpinx as visualised through endoscopic techniques, $40 \%$ percent had endometrial changes like caseation, pyometra, $18 \%$ had both endometrial and intraluminal pathology.

Table 1: Showing correlation between male and female genital $\mathbf{T B}$.

\begin{tabular}{|ll|}
\hline Total Male patients & 100 \\
\hline Males who tested positive for TB & $35(35 \%)$ \\
\hline $\begin{array}{l}\text { Females partners who tested } \\
\text { positive for TB }\end{array}$ & 6 out of $35(18 \%)$ \\
\hline
\end{tabular}

Out of the total 35 male patients who tested positive for T.B. $18 \%$ positive females were noted and a positive correlation was established as depicted above.

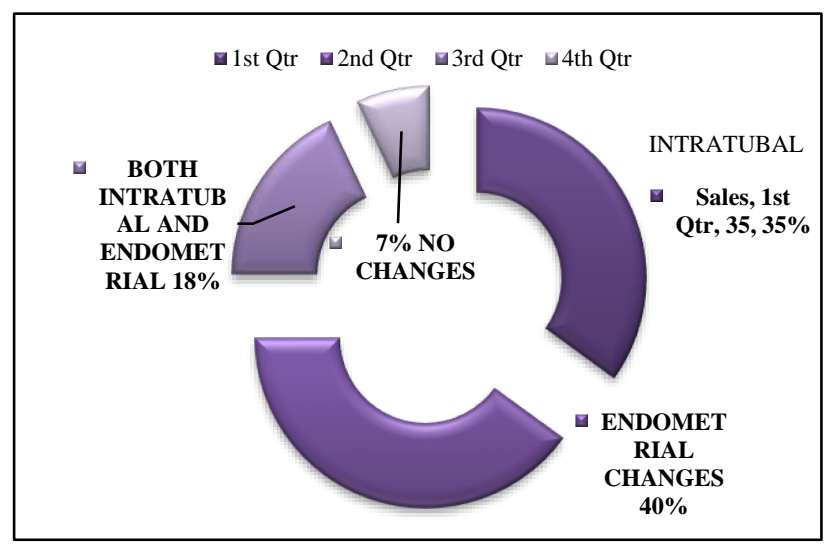

Figure 3: Hysteroscopic findings of tubercular patients. 


\section{DISCUSSION}

Genital TB can present at any age, although it commonly affects men at 30-50 years and is uncommon in children due to long latency periods. ${ }^{11-15}$ Clinical presentation may range from a painless scrotal mass, which is the commonest, to irritative lower urinary tract symptoms, hematuria, dysuria, hemospermia, infertility, ulcerative penile lesion to being completely asymptomatic and incidentally diagnosed on histopathology. ${ }^{16,17}$ Patients may have symptoms of associated upper tract disease but constitutional symptoms per se are less common and may suggest an extra-genital disease. ${ }^{16,18}$

Male infertility presenting as severe oligoospermia and azoospermia is a diagnostic and therapeutic challenge to fertility experts hoping to bring joy to lives of infertile couples. Unfortunately men suffering from genitourinary TB often go undiagnosed resulting in poor fertilization rates and reproductive outcome even after utilizing the highest of ART including ICSI. The danger of early pregnancy loss/fetal abnormality remains even after conception for obvious reasons. It is well known fact that a large proportion of wives of azoospermic men struggle to conceive. In this study it has been found that out of a total 100 males with oligospermia/azoospermia, 35\% had proven male genital TB. Out of these 35 males, 6 (18\%) females had proven female genital TB establishing a correlation between the two. In Russia more than 10,000 men annually are diagnosed with prostatic tuberculosis, which again has become a sexually transmitted disease and prostate tuberculosis is one of the main reasons for infertility- both male and female. ${ }^{19,20}$ As per Baxi et al $30 \%$ couples had both male and female genital tuberculosis simultaneously and also that there is a possibility that mycobacterium subclinically resides in male or female genital tract and gets sexually transmitted particularly from males to females via seminal fluid and may contribute to both male and female factor infertility. ${ }^{21}$ An important aspect of genital infections in male may be that male accessory sex glands may act as reservoirs for the organism, increasing possibility of transmission to the females.

Timely diagnosis of this condition and treatment of the infertile couple can bring abundance of happiness and hope to their lives. Hence it would be worthwhile investigating both the partners on the line of tuberculosis if genital TB is suspected in one.

It is also essential to emphasize that available studies in the literature do show strong correlation between both male and female infertility but there is limited data available comparing potential mutual transmission between the couples. Hence this present study had been undertaken.

Small sample size and long duration of study were the limiting factors.

\section{CONCLUSION}

Tubercular work up of both partners is desired in couples with male factor infertility especially in long standing infertility to achieve optimum pregnancy outcome with ART.

Funding: No funding sources

Conflict of interest: None declared

Ethical approval: The study was approved by the Institutional Ethics Committee

\section{REFERENCES}

1. World Health Organization (2018). Global tuberculosis report 2018. World Health Organization. Available from: https://apps.who.int/iris/handle/ 10665/274453. Accessed on 3 December 2019.

2. Central TB Division, Directorate General of Health Services. India TB. Report: Revised National Tuberculosis Control Programme: Annual status report. New Delhi. Ministry of Health and Family Welfare; 2018.

3. Golden MP, Vikram HR. Extrapulmonary tuberculosis: An overview. Am Fam Phys. 2005;72:1761-8.

4. Kumar S, Sharma JB. Female genital tuberculosis. In: Sharma SK, Mohan A, eds. Tuberculosis, 3rd edn. Delhi: Jaypee; 2015:362-371.

5. Neonakis IK, Spandidos DA, Petinaki E. Female genital tuberculosis: A review. Scand J Infect Dis. 2011;43:564-72.

6. Sharma JB. Tuberculosis and obstetric and gynecological practice. In: Studd J, Tan SL, Chervenak FA, eds. Progress in obstetrics and gynaecology, Vol. 18. Philadelphia: Elsevier; 2008:395-427.

7. Sharma JB. Current diagnosis and management of female genital tuberculosis. J Obstet Gynaecol India. 2015;65:362-71.

8. Gorse GJ, Belshe RB. Male genital tuberculosis: a review of the literature with instructive case reports. Rev Infect Dis. 1985;7(4):511-24.

9. Jacob JT, Nguyen TM, Ray SM. Male genital TB. Lancet Infect Dis. 2008;8(5):335-42.

10. Shah HU, Sannananja B, Baheti AD, Udare AS, Badhe PV. Hysterosalpingography and ultrasonography findings of female genital tuberculosis. Diagnost Intervent Radiol. 2015;21(1): 10 .

11. Abbara A, Davidson RN. Etiology and management of genitourinary tuberculosis. Nat Rev Urol. 2011;8:678-88.

12. Figueiredo AA, Lucon AM. Urogenital tuberculosis: update and review of 8961 cases from world literature. Rev Urol. 2008;10:207-17.

13. Kulchavenya E, Khomyakov V. Male genital tuberculosis in Siberians. World $\mathrm{J}$ Urol. 2006;24:74-8. 
14. Gupta NP, Kumar R, Mundada OP, Aron M, Hemal AK, Dogra PN, et al. Reconstructive surgery for the management of genitourinary tuberculosis: a single center experience. J Urol. 2006;175:2150-4.

15. Gorse GJ, Belshe RB. Male genital tuberculosis: a review of the literature with instructive case reports. Rev Infect Dis. 1985;7:511-24.

16. Hemal AK, Aron M. Orthotopic neobladder in management of tubercular thimble bladders: initial experience and long-term results. Urology. 1999;53:298-301.

17. Jacob JT, Nguyen TM, Ray SM. Male genital tuberculosis. Lancet Infect Dis. 2008;8:335-42.

18. Christensen WI. Genitourinary tuberculosis. Review of 102 cases. Medicine. 1974;53:377-90.

19. Aphonin A, Perezmanas E, Toporkova E, Khodakovsky E. Tuberculous infection as sexually transmitted infection. Vestnik Poslediplomnogo Obrazovaniya. 2006;3-4:69-71.

20. Kulchavenya E. Male Genital Tuberculosis. In: Urogenital Tuberculosis: Epidemiology, Diagnosis, Therapy. Springer, Cham; 2014:83-93.

21. Baxi A, Neema H, Kadi P, Baxi D, Kaushal M. Prevalence of male genital tuberculosis in indian infertile couples and its correlation with female genital tuberculosis. J South Asian Feder Obst Gynaecol. 2016;8(1):13-5.

Cite this article as: Chaudhary A, Kaur P, Kansal R, Dhillon V, Bansal I. Correlation between male and female genital tuberculosis: a prospective analytical study. Int J Reprod Contracept Obstet Gynecol 2021;10:1053-6. 